\title{
Over half of breakpoints in gene pairs involved in cancer-specific recurrent translocations are mapped to human chromosomal fragile sites
}

\author{
Allison A Burrow ${ }^{1}$, Laura E Williams ${ }^{1}$, Levi CT Pierce ${ }^{2}$ and Yuh-Hwa Wang*1
}

Address: ${ }^{1}$ Department of Biochemistry, Wake Forest University School of Medicine, Medical Center Boulevard, Winston-Salem, NC 27157-1016, USA and ${ }^{2}$ Department of Electrical Engineering and Computer Science, University of Kansas, Lawrence, KS 66045-7612, USA

Email: Allison A Burrow - aburrow@wfubmc.edu; Laura E Williams - lawillia@wfubmc.edu; Levi CT Pierce - levipierce@gmail.com; YuhHwa Wang* - ywang@wfubmc.edu

* Corresponding author

Published: 30 January 2009

BMC Genomics 2009, 10:59

This article is available from: http://www.biomedcentral.com//47/-2/64/10/59

(c) 2009 Burrow et al; licensee BioMed Central Ltd.

This is an Open Access article distributed under the terms of the Creative Commons Attribution License (http://creativecommons.org/licenses/by/2.0), which permits unrestricted use, distribution, and reproduction in any medium, provided the original work is properly cited.
Received: 27 August 2008
Accepted: 30 January 2009

\begin{abstract}
Background: Gene rearrangements such as chromosomal translocations have been shown to contribute to cancer development. Human chromosomal fragile sites are regions of the genome especially prone to breakage, and have been implicated in various chromosome abnormalities found in cancer. However, there has been no comprehensive and quantitative examination of the location of fragile sites in relation to all chromosomal aberrations.

Results: Using up-to-date databases containing all cancer-specific recurrent translocations, we have examined 444 unique pairs of genes involved in these translocations to determine the correlation of translocation breakpoints and fragile sites in the gene pairs. We found that over half (52\%) of translocation breakpoints in at least one gene of these gene pairs are mapped to fragile sites. Among these, we examined the DNA sequences within and flanking three randomly selected pairs of translocation-prone genes, and found that they exhibit characteristic features of fragile DNA, with frequent AT-rich flexibility islands and the potential of forming highly stable secondary structures.
\end{abstract}

Conclusion: Our study is the first to examine gene pairs involved in all recurrent chromosomal translocations observed in tumor cells, and to correlate the location of more than half of breakpoints to positions of known fragile sites. These results provide strong evidence to support a causative role for fragile sites in the generation of cancer-specific chromosomal rearrangements.

\section{Background}

Tumor cells exhibit various forms of genomic instability, including chromosomal rearrangements, many of which directly contribute to the neoplastic process rather than occurring as a consequence [1,2]. Rearrangements causing the deletion, insertion or translocation of genetic material often result in the expression of altered gene products with oncogenic potential, or the loss of tumor suppressive functions. Although the mechanisms of these processes remain elusive, it is evident that DNA breakage is an initiating event.

There are a variety of ways by which a cell acquires DNA breaks. Breaks can arise from any agent that affects the pri- 
mary structure of the double helix, like endogenous reactive oxygen species or exogenous factors such as ionizing radiation [3]. More recent reports suggest that, in addition, regions of the genome especially susceptible to breakage termed "fragile sites" may also cause DNA strand breakage. One study using chromosome banding has provided compelling evidence supporting a role for fragile sites in cancer development by demonstrating a significant association between sites of chromosome rearrangements found in tumor cells and fragile sites [4]. Therefore, it has been proposed that fragile sites may contribute to the genetic instability observed in cancer cells [5], but a direct role has not yet been proven.

Fragile sites are defined as non-random chromosomal loci that exhibit gaps and breaks on metaphase chromosomes under conditions which partially inhibit DNA synthesis [6]. Fragile sites are classified as common or rare, depending on their frequency in the population, and are further divided according to their mode of induction in cultured cells. Common fragile sites are present in all individuals, and are therefore believed to represent a normal component of chromosome structure [7]. In contrast, rare fragile sites are found in less than 5\% of the population, and are inherited in a Mendelian manner [8,9]. To date, about 121 different fragile sites have been identified, but the number may increase. The majority of fragile sites can be induced by environmental agents and chemicals, including caffeine, alcohol and cigarette smoke [6]. Variability of fragile site breakage has been observed within individuals [10], which may reflect exposure to such factors, with high levels being associated with cancer [11]. Many genes located within or spanning these sites have been identified as tumor suppressors or oncogenes, and fragile sites have been found to be preferential targets of environmental mutagens and carcinogens [12]. Numerous studies have also revealed a significant association between the location of fragile sites and sites of a limited number of chromosome defects in cancer cells [13-15]. Moreover, Durkin et al. demonstrated that the deletions of the type seen in cancer can be produced within fragile site FRA3B, a site of rearrangements and deletions that are among the most common type of aberrations found in tumors [16], further supporting a role for fragile sites in cancer development.

Although the mechanisms of fragile site breakage are still unclear, several factors have been identified which contribute to fragile site instability. Studies have shown that a deficiency of proteins in the ATR-dependent cell cycle checkpoint pathway dramatically increases fragile site breakage [14]. In addition, all fragile DNA sequences examined so far demonstrate significantly high flexibility [17], and are comprised of AT-rich flexibility islands that can readily fold into stable secondary structures capable of perturbing DNA replication [17,18]. Moreover, all fragile sites studied to date, including FRAXA [19], FRA7H [20], FRA3B [21], FRA10B [22], and FRA16B [22] have been identified as late-replicating regions of the genome.

It is not entirely clear why fragile sites are susceptible to delayed replication, but it has been proposed that the flexible, AT-rich DNA sequences cause the replication fork to pause or stall at sites of secondary structure formation [23]. Supporting this hypothesis, Zhang and Freudenreich demonstrated that a polymorphic AT-dinucleotide repeat capable of forming a cruciform structure within fragile site FRA16D stalls replication fork progression in yeast, leading to increased chromosome breakage [24]. Collectively, these results suggest a shared molecular basis among fragile sites, indicating that the DNA sequences within these regions can present significant difficulties to the replication machinery, and require the activation of DNA damage checkpoint proteins. Fragile sites are therefore believed to represent unreplicated regions of the genome that have escaped the replication checkpoint, and are visible as gaps and breaks on metaphase chromosomes [25].

Although strong correlations have been made between the sites of breakage in a limited number of chromosome rearrangements and the position of fragile sites, there has been no systematic demonstration of fragile site locations relative to breakpoints in all known chromosome aberrations. Due to the availability of extensive databases containing chromosome abnormalities found in various types of tumors, and the increasing number of fragile sites being mapped, we have compiled a table of recurrent translocations in which each participating gene set generates cancer-specific fusion transcripts, and mapped their breakpoints to fragile sites. We found that in more than half $(52 \%)$ of the translocation-participating gene sets, breakpoints within either one or both genes are located at fragile sites. These results suggest that chromosome fragility, particularly at fragile sites, may contribute to the generation of fusion transcripts in cancer cells. Furthermore, we have analyzed the DNA sequences at and around translocation-prone genes mapped to fragile sites for helix flexibility and the potential to form secondary structures. Our results demonstrate that the DNA sequences contain frequent AT-rich flexibility islands, and are capable of forming highly stable secondary structures, supporting their propensity for breakage.

\section{Results \\ Breakpoints in over half (52\%) of gene pairs involved in cancer-specific recurrent translocations are mapped to fragile sites}

To comprehensively investigate the relationship between fragile sites and translocation breakpoints found in cancer, we examined all chromosome defects associated with 
various types of tumors, and identified recurrent translocations in which translocation breakpoints in either one or both participating genes co-localize with a fragile site. Taking advantage of the comprehensive databases already available, we examined a total of 444 different sets of translocation-participating genes involved in 451 translocations obtained from the "Translocation breakpoints In Cancer database" (TICdb) [26] and Mitelman Database of Chromosome Aberrations in Cancer [27]. We identified all genes involved in translocations that mapped to fragile sites, and compared the position of each breakpoint to fragile sites (Additional file 1). The types of fragile sites, rare or common, were also documented in Additional file 1. We found that $52(12 \%)$ translocation-participating gene pairs have breakpoints for which both genes colocalize with fragile sites (Table 1), and 177 (40\%) gene sets contain one gene for which the translocation breakpoint is located at a fragile site (Additional file 2). Therefore, we concluded that a significant number (52\%) of gene pairs involved in cancer-specific recurrent translocations have at least one gene mapped to fragile sites. The majority (65\%) of translocation breakpoints are located at common fragile sites, as opposed to rare sites. In Table 1 , the partner genes in each translocation-participating pair are specified as $5^{\prime}$ or $3^{\prime}$ for the position in which they appear in the cancer-specific fusion transcript, and the types of cancer for each gene pair are listed. Interestingly, the table shows that some genes involved in translocations, like MLL and EWSR1, are most often found at the 5' end of the fusion product. Our data also indicate that fragile sites are involved in the abnormalities seen in a variety of cancers including leukemias, lymphomas, and other solid tumors, such as those of thyroid, breast, and lung.

\section{Translocation-prone genes exhibit characteristics of fragile sites}

Fragile sites have been shown to contain intrinsic features within the DNA sequence that confer a predisposition to fragility [28]. Most fragile sites sequenced to date contain highly flexible sequences and AT-rich islands, with the potential to form secondary structures, which are significantly more stable than same-length random DNA sequences $[17,18]$. Therefore, to determine whether genes involved in cancer-specific recurrent translocations exhibit properties of fragile sites, we analyzed three gene pairs from Table 1 (CBFB/MYH11, HMGA1/LAMA4, and $M L L / A F F 4$ ), and their flanking sequences, for flexibility, $\mathrm{A} / \mathrm{T}$ content, and the propensity to form stable secondary structures. Using the FlexStab program, we found that, with the exception of the MYH11 locus (Figure 1), DNA sequences with significantly high flexibility occur more frequently within the regions harboring translocationprone genes than is predicted for control DNA [17]. The control DNA, from various regions of the human genome where no fragile sites were identified, contains approxi- mately one high-flexibility peak every $100 \mathrm{~kb}$ [17]. Further sequence composition analysis demonstrated that the sequences within the flexibility peaks consist of a very high A/T content (Table 2), similar to what was previously reported for fragile site regions $(78 \% \pm 1.4 \%)$, which is significantly different from that of nonflexible sequences $(61 \% \pm 3.6 \%)(P<0.001)$ [18]. In addition, these sequences are rich in AT-dinucleotides (Table 2) to the same extent as found in the flexible peaks of fragile site regions $(21 \% \pm 0.5 \%)$, as compared to nonflexible DNA $(8 \% \pm 1 \%)[18]$. Further, the secondary structure prediction analysis showed that the sequences within and surrounding genes participating in cancer-specific translocations can readily form highly stable secondary structures, as indicated by their $\Delta \mathrm{G}$ values (Table 2 ) and predicted structures (Figure 2 and Additional file 3). Overall, our results demonstrate that the three gene pairs examined display characteristics of fragile DNA, which could lead to DNA breakage, supporting the notion that fragile sites may participate in the generation of chromosome rearrangements.

\section{Discussion}

Research on understanding the significance of human chromosomal fragile sites in cancer has been very active. Fragile sites are most commonly associated with deletion breakpoints in tumor cells, while few translocations involving these sites have been reported. A limited number of translocation breakpoints have been reported near fragile sites, suggesting that chromosome fragility at these sites may contribute to these rearrangements [29]. Our study herein provides a comprehensive survey of all cancer-specific translocations to date. Therefore, by demonstrating that breakpoints in over half (52\%) of the gene pairs co-map to fragile sites, these results provide strong evidence to support a role for fragile sites in the generation of cancer-specific translocations. It is important to note that we have chosen to focus on translocations and deletions leading to fusion transcripts, and have not included other types of rearrangements such as single gene deletions, insertions, or complex translocations. We have found that many of the genes examined in this study are commonly involved in these other types of rearrangements, like deletion of the FHIT gene located within fragile site FRA3B, and in some cases, the same set of genes is involved in multiple translocations observed in a variety of cancers. An interesting observation was that some genes located near fragile sites, such as NUP98 (11p15.4) which participates in twenty-two different translocations examined, could not be included in Additional file 1, because the gene was not located directly at a fragile site. Recently described fragile sites, like FRA6H at 6p21 [30], have been identified after discovering an association between the chromosome location and sites of recurrent aberrations in disorders. This suggests that $11 \mathrm{p} 15.4$ could be a fragile site 
Table I: Translocation breakpoints mapped to fragile sites in both partner genes of recurrent cancer-specific translocations

\begin{tabular}{|c|c|c|c|c|c|}
\hline & & 5'-b & & 3'-b & \\
\hline Translocation $^{\mathbf{a}}$ & Gene & Fragile Site & Gene & Fragile Site & Cancerc \\
\hline $\mathrm{t}(2 ; \mid 8)(\mathrm{p} \mid \mathrm{I} ; \mathrm{q} 21)$ & $\mathrm{BCL} 2$ & FRAI8B & IGK@ & FRA2L & Diffuse large B-cell lymphoma \\
\hline$t(16 ; 16)(p \mid 3 ; q 22), \operatorname{inv}(16)(p \mid 3 q 22)$ & CBFB & FRAI6B, FRAI6C & MYHII & FRAI6A & Acute myeloid leukemia \\
\hline $\operatorname{inv}(\mid 0)(q|| q 2 I)$ & CCDC6 & FRAIOC & RET & FRAIOG & Papillary thyroid carcinoma \\
\hline$t(I I ; \mid 9)(q|3 ; p| 3)$ & CCNDI & FRAIIH & FSTL3 & FRAI9B & Chronic lymphocytic leukemia \\
\hline $\mathrm{t}(2 ; 7)(\mathrm{p} I \mathrm{I} ; \mathrm{q} 2 \mathrm{I})$ & CDK6 & FRA7E & IGK@ & FRA2L & $\begin{array}{c}\text { B-cell lymphoma, Chronic lymphocytic } \\
\text { leukemia }\end{array}$ \\
\hline $\mathrm{t}(7 ; 1 \mathrm{I})(\mathrm{q} 21 ; q 23)$ & CDK6 & FRA7E & MLL & FRAIIB, FRAIIG & Acute lymphoblastic leukemia \\
\hline $\mathrm{t}(5 ; 7)(\mathrm{q} 35 ; \mathrm{q} 2 \mathrm{l})$ & CDK6 & FRA7E & TLX3 & FRA5G & Acute lymphoblastic leukemia \\
\hline $\mathrm{t}(12 ; 22)(q|3 ; q| 2)$ & EWSRI & FRA22B & ATFI & FRAI $2 A$ & Soft tissue tumor \\
\hline $\mathrm{t}(2 ; 22)(\mathrm{q} 33 ; \mathrm{q} \mid 2)$ & EWSRI & FRA22B & CREBI & FRA2I & Angiomatoid fibrous histiocytoma \\
\hline $\operatorname{inv}(22)(q|2 q| 2)$ & EWSRI & FRA22B & PATZI & FRA22B & Small round cell tumor \\
\hline $\mathrm{t}(6 ; 22)(\mathrm{p} 21 ; q \mid 2)$ & EWSRI & FRA22B & POU5FI & FRA6H & Undifferentiated bone tumor \\
\hline $\mathrm{t}(2 ; 22)(q 3 I ; q \mid 2)$ & EWSRI & FRA22B & SP3 & FRA2G & Ewing tumor/small round cell tumor \\
\hline $\mathrm{t}(1 \mid ; 22)(p|3 ; q| 2)$ & EWSRI & FRA22B & WTI & FRAIIE & Soft tissue tumor \\
\hline $\operatorname{del}(4)(q|2 q| 2)^{d}$ & FIPILI & FRA4B & PDGFRA & FRA4B & Hypereosinophilic syndrome \\
\hline $\operatorname{inv}(6)(p 2 \mid q 2 I)$ & HMGAI & FRA6H & LAMA4 & FRA6F & Pulmonary chondroid hamartoma \\
\hline $\mathrm{t}(3 ; 6)(q 27 ; p 21)$ & HSP90ABI & FRA6H & BCL6 & FRA3C & B-cell tumors \\
\hline $\mathrm{t}(\mathrm{l} ; 2)(\mathrm{p} 22 ; \mathrm{pl} \mathrm{I})$ & IGK@ & FRA2L & BCLIO & FRAID & B-cell lymphoma \\
\hline $\mathrm{t}(2 ; \mid 9)(p|I ; q| 3)$ & IGK@ & FRA2L & $\mathrm{BCL} 3$ & FRAI9A & Mature B-cell neoplasm \\
\hline $\mathrm{t}(2 ; 3)(\mathrm{p} I \mathrm{I} ; \mathrm{q} 27)$ & IGK@ & FRA2L & BCL6 & FRA3C & $\begin{array}{l}\text { Mature B-cell neoplasm, Follicular } \\
\text { lymphoma }\end{array}$ \\
\hline $\mathrm{t}(2 ; \mid I)(p|I ; q| 3)$ & IGK@ & FRA2L & CCNDI & FRAIIA, FRAIIH & Mature B-cell neoplasm \\
\hline $\mathrm{t}(2 ; \mid 8)(\mathrm{p} \mid \mathrm{I} ; \mathrm{q} 2 \mathrm{I})$ & IGK@ & FRA2L & FVTI & FRAI8B & Follicular lymphoma \\
\hline$t(3 ; 16)(q 27 ; p \mid 2)$ & IL2IR & FRAI6E & BCL6 & FRA3C & Diffuse large B-cell lymphoma \\
\hline $\mathrm{t}(1|;| 9)(q|3 ; q| 3.4)$ & MALATI & FRAIIH & MHLBI & FRAI9A & Undifferentiated embryonal sarcoma \\
\hline $\mathrm{t}(6 ; 1 \mathrm{I})(\mathrm{p} 2 \mathrm{I} . \mathrm{I} ; \mathrm{q} \mid 3)$ & MALATI & FRAIIH & TFEB & FRA6H & Pediatric renal neoplasm \\
\hline $\mathrm{t}(4 ; \mathrm{II})(\mathrm{q} 21.3-22.1 ; \mathrm{q} 23)$ & MLL & FRAIIB, FRAIIG & AFFI & FRA4F & $\begin{array}{c}\text { Acute lymphoblastic leukemia, Acute } \\
\text { myeloid leukemia }\end{array}$ \\
\hline $\mathrm{t}(2 ; 1 \mathrm{I})(\mathrm{qI} I ; q 23)$ & MLL & FRAIIB, FRAIIG & AFF3 & FRA2A & Acute lymphoblastic leukemia \\
\hline
\end{tabular}


Table I: Translocation breakpoints mapped to fragile sites in both partner genes of recurrent cancer-specific translocations (Continued)

\begin{tabular}{|c|c|c|c|c|c|}
\hline $\mathrm{t}(5 ; 1 \mathrm{I})(\mathrm{q} 3 \mathrm{I} ; \mathrm{q} 23)$ & MLL & FRAIIB, FRAIIG & AFF4 & FRA5C & Acute lymphoblastic leukemia \\
\hline $\operatorname{del}(1 \mathrm{I})(\mathrm{q} 23 \mathrm{q} 23)^{d}$ & MLL & FRAIIB, FRAIIG & ARHGEFI2 & FRAIIB, FRAIIG & Acute myeloid leukemia \\
\hline $\mathrm{t}(\mathrm{II} ; \mathrm{II})(\mathrm{q} \mid 3 ; q 23)$ & MLL & FRAIIB, FRAIIG & ARHGEFI7 & FRAIIH & Acute myeloid leukemia \\
\hline $\operatorname{del}(I I)(q 23 q 23)^{d}$ & MLL & FRAIIB, FRAIIG & $\mathrm{CBL}$ & FRAIIB, FRAIIG & Acute myeloid leukemia \\
\hline $\mathrm{t}(1 \mathrm{I} ; 19)(q 23 ; p \mid 3)$ & MLL & FRAIIB, FRAIIG & ELL & FRAI9B & Acute myeloid leukemia \\
\hline $\mathrm{t}(1 \mathrm{I} ; 22)(\mathrm{q} 23 ; \mathrm{q} \mid 3)$ & MLL & FRAIIB, FRAIIG & EP300 & FRA22A & Acute myeloid leukemia \\
\hline $\mathrm{t}(\mathrm{I} ; 1 \mathrm{I})(\mathrm{p} 32 ; \mathrm{q} 23)$ & MLL & FRAIIB, FRAIIG & EPSI5 & FRAIB & Acute myeloid leukemia \\
\hline $\mathrm{t}(6 ; 1 \mathrm{I})(\mathrm{q} 21 ; q 23)$ & MLL & FRAIIB, FRAIIG & $\mathrm{FOXO3A}$ & FRA6F & Acute myeloid leukemia \\
\hline $\mathrm{t}(3 ; 1 \mathrm{I})(\mathrm{q} 25 ; \mathrm{q} 23)$ & MLL & FRAIIB, FRAIIG & GMPS & FRA3D & Acute myeloid leukemia \\
\hline $\mathrm{t}(\mathrm{II} ; 14)(q 23 ; q 23)$ & MLL & FRAIIB, FRAIIG & GPHN & FRAI4B & Acute myeloid leukemia \\
\hline $\mathrm{t}(1 \mathrm{I} ; 19)(\mathrm{q} 23 ; \mathrm{p} \mid 3.3)$ & MLL & FRAIIB, FRAIIG & MLLTI & FRAI9B & Acute myeloid leukemia \\
\hline $\mathrm{t}(\mathrm{I} ; \mathrm{II})(\mathrm{q} 2 \mathrm{I} ; \mathrm{q} 23)$ & MLL & FRAIIB, FRAIIG & MLLTII & FRAIF & Acute myeloid leukemia \\
\hline $\mathrm{t}(9 ; 1 \mathrm{I})(\mathrm{p} 21 ; \mathrm{q} 23)$ & MLL & FRAIIB, FRAIIG & MLLT3 & FRA9A, FRA9C & Acute myeloid leukemia \\
\hline $\mathrm{t}(1 \mathrm{I} ; 19)(q 23 ; p \mid 3)$ & MLL & FRAIIB, FRAIIG & MYOIF & FRAI9B & Acute myeloid leukemia \\
\hline $\operatorname{inv}(I I)(q \mid 4 q 23)$ & MLL & FRAIIB, FRAIIG & PICALM & FRAIIF & Acute myeloid leukemia \\
\hline $\mathrm{t}(2 ; \mathrm{II})(\mathrm{q} 37 ; \mathrm{q} 23)$ & MLL & FRAIIB, FRAIIG & SEPT2 & FRA2 J & Acute myeloid leukemia \\
\hline $\mathrm{t}(1 \mathrm{I} ; 19)(q 23 ; p \mid 3)$ & MLL & FRAIIB, FRAIIG & SH3GLI & FRAI9B & Acute myeloid leukemia \\
\hline $\mathrm{t}(6 ; 1 \mathrm{I})(\mathrm{q} \mid 3 ; q 23)$ & MLL & FRAIIB, FRAIIG & SMAPI & FRA6D & Acute myeloid leukemia \\
\hline $\mathrm{t}(10 ; 11)(q 21 ; q 23)$ & MLL & FRAIIB, FRAIIG & TETI & FRAIOC & Acute myeloid leukemia \\
\hline $\mathrm{t}(9 ; 9)(\mathrm{p} 21 ; \mathrm{p} 21)$ & MTS2 & FRA9A, FRA9C & MTSI & FRA9A, FRA9C & Acute lymphoblastic leukemia \\
\hline $\operatorname{inv}(I 0)(q \mid I q I I)$ & NCOA4 & FRAIOG & RET & FRAIOG & Papillary thyroid carcinoma \\
\hline $\mathrm{t}(3 ; 5)(q 25 ; \mathrm{q} 35)$ & NPMI & FRA5G & MLFI & FRA3D & Acute myeloid leukemia \\
\hline $\mathrm{t}(3 ; 6)(\mathrm{q} 27 ; \mathrm{p} 2 \mathrm{l})$ & PIMI & FRA6H & $\mathrm{BCL} 6$ & FRA3C & Diffuse large B-cell lymphoma \\
\hline $\mathrm{t}(3 ; 6)(\mathrm{q} 27 ; \mathrm{p} 2 \mathrm{I})$ & SFRS3 & FRA6H & $\mathrm{BCL} 6$ & FRA3C & Follicular lymphoma \\
\hline$t(19 ; \mid 9)(p|3 ; q| 3)$ & TCF3 & FRAI9B & TFPT & FRAI9A & Acute lymphoblastic leukemia \\
\hline $\operatorname{inv}(I)(q 2 I q 3 I)$ & TPM3 & FRAIF & TPR & FRAIK & Papillary thyroid carcinoma \\
\hline
\end{tabular}

aThe translocation names for each unique gene set are indicated.

bPosition in which the gene appears in the cancer-specific fusion transcript

cFor a complete description, see the Mitelman database of Chromosome Aberrations in Cancer [27].

dDeletions creating a fusion between two genes 
Table 2: Computational analysis of genes involved in cancer-specific recurrent translocations reveals characteristics of chromosomal fragile sites

\begin{tabular}{|c|c|c|c|c|}
\hline \multirow[b]{2}{*}{ Gene } & \multicolumn{3}{|c|}{ FlexStab } & \multirow{2}{*}{$\begin{array}{c}\text { MFOLD } \\
\text { Lowest } \Delta \text { G value }{ }^{\mathrm{a}}(\mathrm{kcal} / \mathrm{mol})\end{array}$} \\
\hline & Number of flexibility peaks/Kb & $\% \mathbf{A} / \mathbf{T}$ & $\%$ AT-dinucleotides & \\
\hline CBFB & $4 / 322$ & $79 \pm 3.9$ & $24 \pm 3.0$ & -|| $6.9 \mid$ \\
\hline MYHII & $4 / 404$ & $78 \pm 5.5$ & $23 \pm 5.9$ & -97.02 \\
\hline HMGAI & $6 / 259$ & $81 \pm 7.8$ & $24 \pm 3.6$ & -124.07 \\
\hline LAMA4 & $9 / 397$ & $78 \pm 2.7$ & $23 \pm 3.0$ & -59.2 \\
\hline MLL & $5 / 339$ & $78 \pm 10.2$ & $23 \pm 4.8$ & -100.74 \\
\hline AFF4 & $4 / 338$ & $81 \pm 3.3$ & $26 \pm 3.1$ & -100.97 \\
\hline Fragile site & & $78 \pm 1.4 \mathrm{c}$ & $21 \pm 0.5^{c}$ & \\
\hline Control & $1 / 100^{b}$ & $61 \pm 3.6^{c}$ & $8 \pm 1.0^{c}$ & $-41.79 d$ \\
\hline
\end{tabular}

aLowest $\Delta G$ value, predicted by MFOLD

bMishmar et al. [17] examined I.I Mb of non-fragile DNA, and showed that regions with significantly high flexibility occur every $\sim 100 \mathrm{~kb}$.

cZlotorynski et al. [18]

TThe LAMA4 sequence was randomized 1000 times to serve as a control, and then analyzed by MFOLD.

that has not yet been identified, or that the proximal fragile sites FRA11C and FRA11I at 11p15.1 are larger than previously determined. Therefore, it is appropriate to assume that the total number of chromosomal aberrations in cancer associated with fragile sites could be even greater than presented in this study, arguing for the significance of the involvement of fragile sites in tumorigenesis.

In addition to solidifying the role of fragile sites participating in cancer development, this study also supports the common hypothesis for the molecular basis of fragility at these sites. We have shown that the DNA sequences within and surrounding three pairs of translocation-prone genes exhibit features of fragility. On average, peaks of significantly high flexibility occur more often than in random DNA, which is consistent with previous results [17]. We also found these peaks to have a high $\mathrm{A} / \mathrm{T}$ content and to be rich in AT-dinucleotides to the same extent as established in fragile sites [18]. Furthermore, our data from the MFOLD program indicate that the sequences have the potential to form highly stable secondary structures, another distinct characteristic of fragile sites [18], which could disturb progression of the replication fork. Based on our results, and the proposed mechanism of fragile site expression, it is likely that the AT-rich flexibility islands within or flanking translocation-prone genes are able to stall replication by the formation of secondary structures, which may then lead to DNA strand breakage, and ultimately to chromosome rearrangements.
Several proteins involved in the replication checkpoint pathway are essential for maintaining stability at fragile sites [14]. These include the $S$ phase and $G_{2} / M$ checkpoint kinase ATR [25], and its downstream targets BRCA1 [31], FACD2 [32], and CHK1 [33]. ATR is a major component of the checkpoint pathway, where it functions by sensing and responding to DNA damage, including stalled and collapsed replication forks [34,35]. It is hypothesized that ATR maintains fragile site stability by sensing and binding to single-stranded DNA resulting from stalled replication forks [25]. However, in the absence of ATR, the main transducer of the DNA double-strand break (DSB) signal, which is ATM, has been shown to regulate fragile site stability [36], indicating that DSBs also occur at fragile sites. Following breakage, chromosome rearrangements may take place via the homologous recombination (HR), nonhomologous end-joining (NHEJ) DSB repair pathways $[37,38]$, or microhomology-mediated single-strand annealing (SSA) [39]. The repair of lesions at fragile sites is still not clear, but evidence suggests that all three pathways may be involved. Based on recent observations made by Lieber et al., it is hypothesized that the sequence-specific RAG complex involved in V(D)J recombination, which is an important process of the NHEJ type, may also recognize and cleave at non-B DNA structures [40], a feature shared by all fragile sites examined to date. Schwartz et al. [41] have shown that induction of fragile sites leads to RAD51 focus formation, and phosphorylation of DNAPKcs, key components of the HR and NHEJ pathways, 

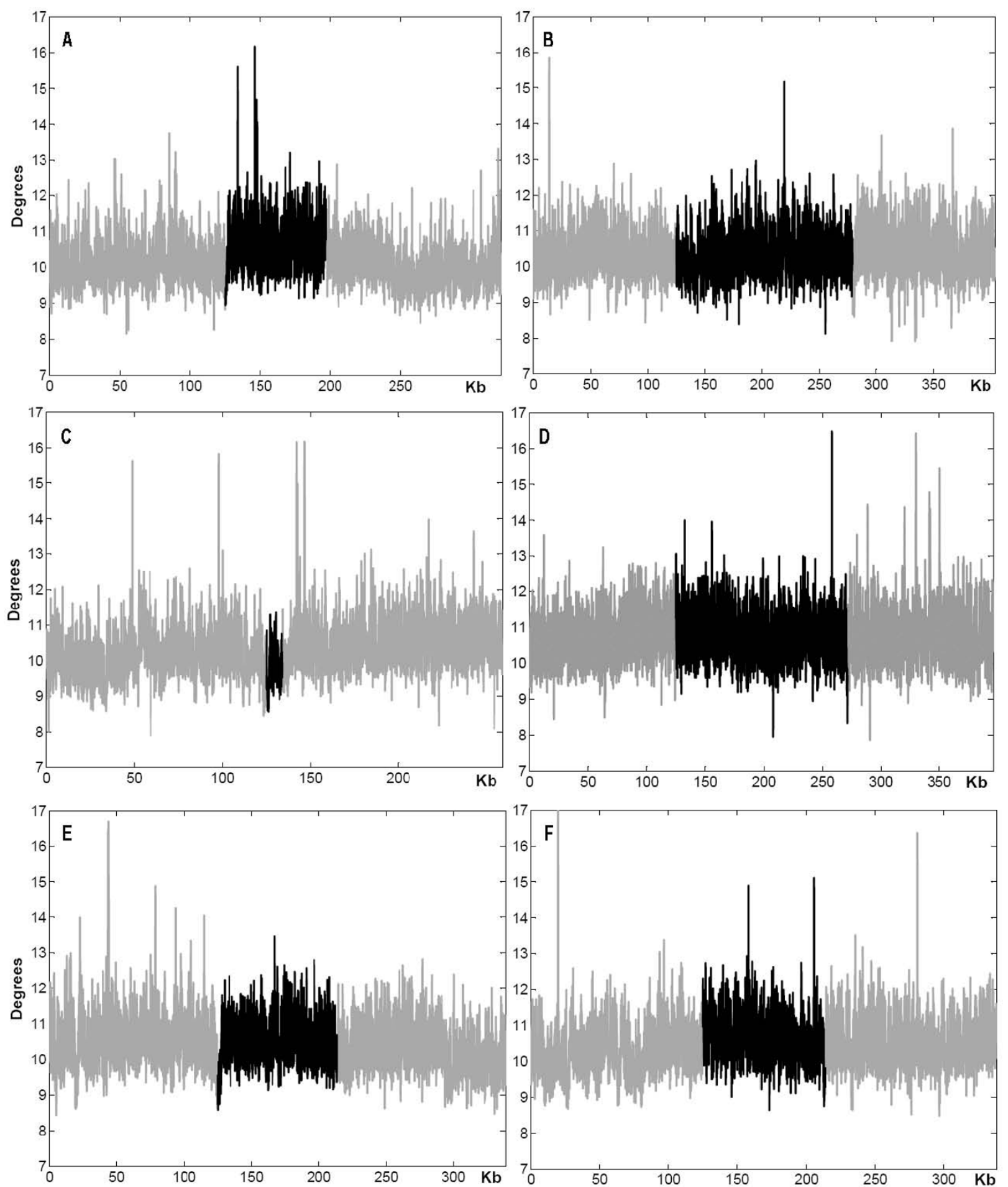

Figure I

DNA flexibility analysis of translocation-prone and fragile site co-localized genes. DNA sequences within and flanking genes (A) CBFB (B) MYHI I (C) HMGA I (D) LAMA4 (E) MLL (F) AFF4 were analyzed using the FlexStab program. The analysis was performed over the length of the entire gene (shaded in black) plus $125 \mathrm{~kb}$ flanking on each side (shaded in gray). The $x$ axis indicates the size of the analyzed sequences, and the $y$ axis shows degrees of inclination in the twist angle. Windows with values $>13.7^{\circ}$ were considered as significantly high flexibility peaks [ 17$]$. 


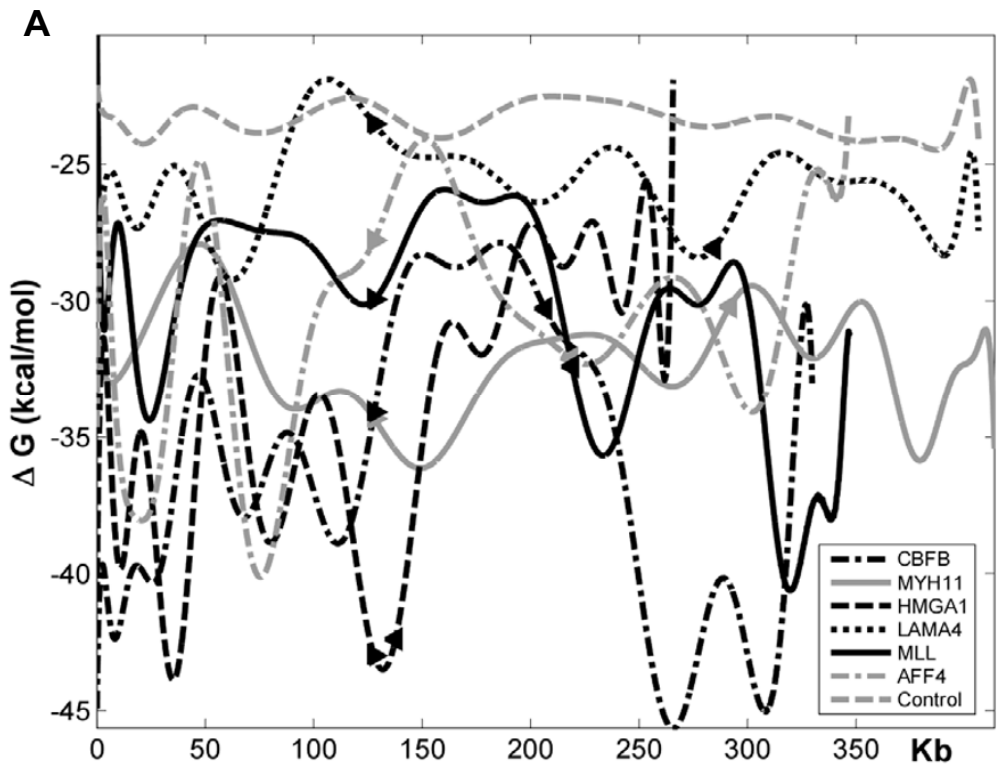

B
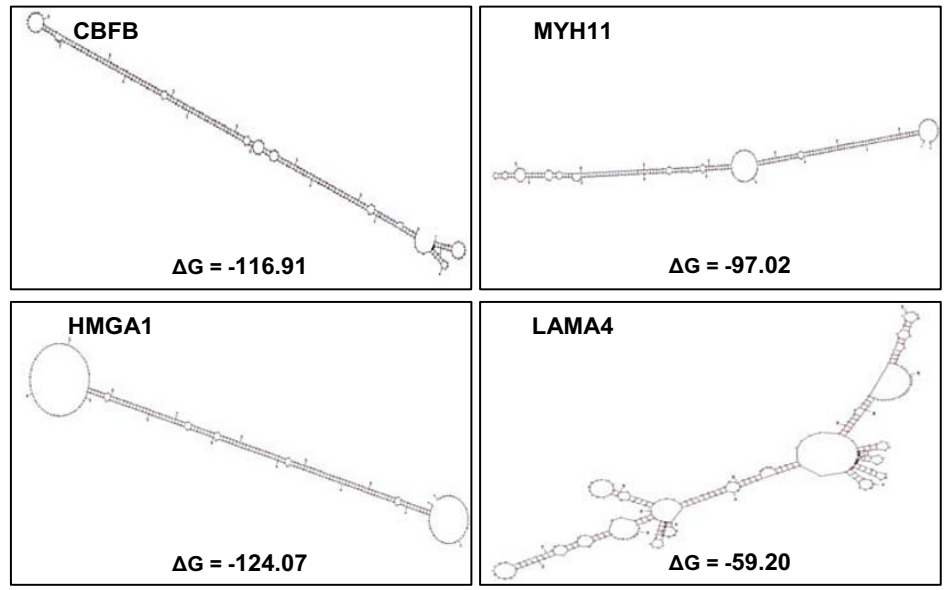

LAMA4
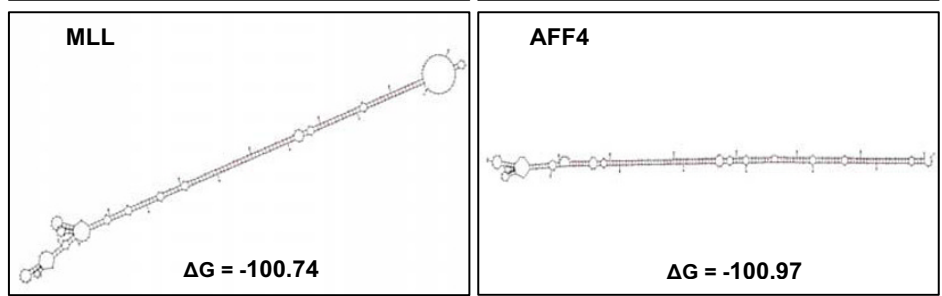

\section{Figure 2}

Secondary structure analysis of CBFB, MYHI I, HMGAI, LAMA4, MLL, and AFF4 loci. (A) Comparison of potential to form secondary structure for these genes versus a control. The computed lowest free energy of predicted DNA secondary structures from segments of $300 \mathrm{nt}$ in length, overlapping in $150 \mathrm{nt}$ steps, has been fit to a curve for each gene. The Matlab function polyfit finds coefficients of a polynomial $P(X)$ of degree $N$ that fit the raw data best in a least-squares sense. The analysis was performed over the length of the entire gene plus $125 \mathrm{~kb}$ flanking on each side. The arrows indicate where a gene begins and ends. The control sequence was generated by randomizing LAMA4 1000 times. The $x$ axis indicates the size of the analyzed sequences, and the $y$ axis displays the free energy of the predicted structure. Raw data plots for each gene are included in Additional file 3. (B) The most stable structure predicted for each gene, as produced by MFOLD. Each structure represents the $300 \mathrm{nt}$ segment with the lowest $\Delta \mathrm{G}$ value. 
respectively. Furthermore, they found that down-regulation of RAD51 and DNA-PKcs increases fragile site instability, suggesting that both HR and NHEJ DSB repair pathways mediate break repair at fragile sites. In addition, the majority of breakpoints in a papillary thyroid carcinoma rearrangement mapped to fragile sites occur at microhomology patches, indicating that fragile site-associated rearrangements can also arise by microhomologymediated SSA [42]. Although the underlying basis of chromosome rearrangements is still unclear, our results show that $39 \%$ of the translocations examined have only one breakpoint mapped to a fragile site, suggesting that gene rearrangements could be achieved with strand breakage at only one gene, as well as at both participating genes. To support this hypothesis, additional studies are needed to obtain a greater understanding of the mechanisms of chromosome rearrangements.

The most intriguing finding from this study is that the majority $(65 \%)$ of fragile sites mapped to translocation breakpoints are common fragile sites, which are present in all individuals, and can be induced by a variety of environmental factors and chemical agents. Interestingly, most cancers associated with the translocations examined in this study have little or no genetic component. These observations suggest that exposure to fragile site-inducing chemicals and/or reduced levels of proteins critical for the maintenance of fragile sites may confer a risk for cancerspecific rearrangements. It will be important to identify factors that contribute to chromosome fragility, such as DNA sequences, proteins and environmental/dietary agents, since fragile sites are sensitive to a range of chemicals. Understanding the molecular basis of fragile sites could therefore allow development of a prognostic assay for cancer risk.

\section{Conclusion}

Our study is the first to comprehensively compare the location of cancer-specific recurrent translocation breakpoints and fragile sites. We showed that breakpoints in over half $(52 \%)$ of the translocation-participating gene pairs co-map to positions of known human chromosomal fragile sites. Furthermore, we demonstrated that the DNA sequences at and surrounding three pairs of translocationprone genes that are mapped to fragile sites, exhibit frequent AT-rich flexibility islands and are capable of forming highly stable secondary structures, both of which are characteristics of fragile DNA. Thus, we have provided a greater understanding of the contribution of fragile sites in the formation of chromosomal translocations, and further supported a role for fragile sites in cancer development.

\section{Methods \\ Data collection}

Two databases were examined encompassing all chromosome rearrangements found in cancer. The freely available TICdb was downloaded from http://www.unav.es/genet ica/TICdb/ (v2.3 May 2008), which contains the breakpoints of cancer-specific reciprocal translocations mapped to over 300 different human genes [26]. In addition, we cross-examined the Mitelman database of Chromosome Aberrations in Cancer, a database relating chromosomal aberrations to tumor characteristics for recurrent translocations using the Molecular Biology Associations search tool [27]. From these databases, 444 different pairs of genes participating in cancer-specific recurrent translocations were obtained. In some cases, the same set of genes is involved in multiple types of translocations. All of these translocations result in one or two cancer-specific fusion genes. For each gene, the chromosomal locus was obtained from the UCSC Genome Bioinformatics website http://genome.ucsc.edu, and compared to the mapped positions of all known fragile sites (http:// www.ncbi.nlm.nih.gov/sites/entrez? $\mathrm{db}=$ gene using "fragile site" as a search term) [30,43-45]. All genes located at fragile sites are highlighted in Additional file 1. The translocation breakpoints of all genes highlighted in Additional file 1 were compared to fragile site positions, to identify translocations in which the site of breakage is colocalized with a fragile site at either one (Additional file 2) or both (Table 1) genes involved in the translocation.

\section{Flexibility analysis}

DNA helix flexibility was assessed using FlexStab, a computer program designed by Mishmar et al. [17], which measures potential local variations in DNA between consecutive base pairs, and is expressed as fluctuations in the twist angle. The analysis was performed over the length of the entire gene plus $125 \mathrm{~kb}$ flanking on each side, in windows of $100 \mathrm{bp}$ with $25 \mathrm{bp}$ shift increments. Windows with values $>13.7^{\circ}$ were considered as significantly high flexibility peaks [17].

Three gene pairs in which both genes are mapped to fragile sites (CBFB/MYH11, HMGA1/LAMA4, and MLL/AFF4) were used for flexibility and secondary structure analysis. The examined sequences for each gene are: $C B F B$ [nucleotides (nt) 20552249 20874160 of GenBank: NT 010498.15], MYH11 [nt 6985071 7388966 of NT 010393.15], HMGA1 [nt 24937900 25197258 of NT_007592.14], LAMA4 [nt 16473563 16870257 of NT 025741.14], MLL [nt 21744621 22083352 of NT 033899.7], and AFF4 [nt 34501084 34839367 of NT 034772.5$]$. 


\section{Assessment of secondary structure}

Using Zukers' MFOLD program [46], the potential of a single-stranded DNA to form stable secondary structure can be predicted along with its free-energy value. For a given gene, $300 \mathrm{nt}$ segments with $150 \mathrm{nt}$ shift increments were used as input for MFOLD. The length of $300 \mathrm{nt}$ was chosen because it equals the Okazaki initiation zone of the DNA replication fork in mammalian cells, which possesses a single-stranded property during DNA replication $[47,48]$. The default $\left[\mathrm{Na}^{+}\right],\left[\mathrm{Mg}^{2+}\right]$, and temperature used were $1.0 \mathrm{M}, 0.0 \mathrm{M}$, and $37^{\circ} \mathrm{C}$, respectively. The program Bioperl http://www.bioperl.org/wiki/Main Page was used to manipulate the sequences, and Matlab (MathWorks) was used to perform the analysis of the data.

\section{Authors' contributions}

$\mathrm{AB}$ and LEW compiled and analyzed the databases. $\mathrm{AB}$ and LCTP carried out the flexibility and secondary structure analyses. $\mathrm{AB}$ and Y-HW wrote the paper. Y-HW designed and coordinated the study. All authors read and approved the final manuscript.

\section{Additional material}

\section{Additional file 1}

Comprehensive list of gene pairs involved in cancer-specific recurrent translocations which result in fusion transcripts. The translocation name(s) for each unique set of genes and the chromosomal locations of all genes are indicated. Genes which co-map to fragile sites are highlighted in gray, and the fragile site is specified.

Click here for file

[http://www.biomedcentral.com/content/supplementary/14712164-10-59-S1.pdf]

\section{Additional file 2}

Gene pairs involved in cancer-specific recurrent translocations in which the breakpoint in one gene co-localizes with a fragile site. The translocation name(s) for each unique gene set is indicated. The gene within each set located at a fragile site is highlighted in gray, and the cancer(s) in which the fusion transcript is found is included.

Click here for file

[http://www.biomedcentral.com/content/supplementary/14712164-10-59-S2.pdf]

\section{Additional file 3}

The computed lowest free energy of predicted DNA secondary structures. The flanking $125 \mathrm{~kb}$ regions are shaded in light gray, and the gene region is shaded in black. The black box indicates the location of the most stable structure found in the sequence. The black line is the curve which best fits the raw data. These curves were generated using the polyfit function of the Matlab program, and are presented in Figure 2A.

Click here for file

[http://www.biomedcentral.com/content/supplementary/14712164-10-59-S3.pdf]

\section{Acknowledgements}

This work was supported in part by Public Health Service grants from the National Cancer Institute (CA85826 and CAII3863 to Y-HW).

\section{References}

I. Gasparini P, Sozzi G, Pierotti MA: The role of chromosomal alterations in human cancer development. J Cell Biochem 2007, 102(2):320-331.

2. Keen-Kim D, Nooraie F, Rao PN: Cytogenetic biomarkers for human cancer. Front Biosci 2008, 13:5928-5949.

3. Weterings $E$, Chen $D J$ : The endless tale of non-homologous end-joining. Cell Res 2008, I 8(I): I |4-I24.

4. Mitelman F, Mertens F, Johansson B: A breakpoint map of recurrent chromosomal rearrangements in human neoplasia. Nat Genet 1997:417-474.

5. O'Keefe LV, Richards RI: Common chromosomal fragile sites and cancer: focus on FRA I6D. Cancer Lett 2006, 232(I):37-47.

6. Richards RI: Fragile and unstable chromosomes in cancer: causes and consequences. TRENDS in Genetics 200I, 17:339-345.

7. Glover TW: Common fragile sites. Cancer Lett 2006, 232(I):4-I2.

8. Kremer EJ, Pritchard M, Lynch M, Yu S, Holman K, Baker E, Warren ST, Schlessinger D, Sutherland GR, Richards RI: Mapping of DNA instability at the fragile $X$ to a trinucleotide repeat sequence p(CCG)n. Science |99|, 252(50|3): |7||-17|4.

9. Sutherland $G R$, Baker E, Richards RI: Fragile sites still breaking. Trends Genet I998, I 4( I 2):50I-506.

10. Craig-Holmes AP, Strong LC, Goodacre A, Pathak S: Variation in the expression of aphidicolin-induced fragile sites in human lymphocyte cultures. Hum Genet 1987, 76(2): I34-I37.

II. Tunca B, Egeli U, Zorluoglu A, Yilmazlar T, Yerci O, Kizil A: The expression of fragile sites in lymphocytes of patients with rectum cancer and their first-degree relatives. Cancer Lett 2000, I 52(2):20I-209.

12. Popescu NC: Genetic alterations in cancer as a result of breakage at fragile sites. Cancer Lett 2003, 192:1-17.

13. Yunis J], Soreng AL: Constitutive fragile sites and cancer. Science 1984, 226(4679): I 199-1204.

14. Durkin SG, Glover TW: Chromosome fragile sites. Annu Rev Genet 2007, 41:169-192.

15. Re A, Cora D, Puliti AM, Caselle M, Sbrana I: Correlated fragile site expression allows the identification of candidate fragile genes involved in immunity and associated with carcinogenesis. BMC Bioinformatics 2006, 7:4I3.

16. Durkin SG, Ragland RL, Arlt MF, Mulle JG, Warren ST, Glover TW: Replication stress induces tumor-like microdeletions in FHIT/FRA3B. Proc Natl Acad Sci USA 2008, 105(I):246-25I.

17. Mishmar D, Rahat A, Scherer SW, Nyakatura G, Hinzmann B, Kohwi $Y$, Mandel-Gutfroind Y, Lee JR, Drescher B, Sas DE, Margalit $H$, Platzer M, Weiss A, Tsui LC, Rosenthal A, Kerem B: Molecular characterization of a common fragile site (FRA7H) on human chromosome 7 by the cloning of a simian virus 40 integration site. Proc Natl Acad Sci USA I998, 95( I4):8I4I-8I 46.

18. Zlotorynski E, Rahat A, Skaug J, Ben-Porat N, Ozeri E, Hershberg R, Levi A, Scherer SW, Margalit H, Kerem B: Molecular basis for expression of common and rare fragile sites. Mol Cell Biol 2003, 23(20):7|43-7|5|.

19. Hansen RS, Canfield TK, Field AD, Mumm S, Laird CD, Gartler SM: A variable domain of delayed replication in FRAXA fragile $X$ chromosomes: $\mathbf{X}$ inactivation-like spread of late replication. Proc Natl Acad Sci USA 1997, 94(9):4587-4592.

20. Hellman A, Rahat A, Scherer SW, Darvasi A, Tsui LC, Kerem B: Replication delay along FRA7H, a common fragile site on human chromosome 7, leads to chromosomal instability. Mol Cell Biol 2000, 20( I 2):4420-4427.

21. Le Beau MM, Rassool FV, Neilly ME, Espinosa R 3rd, Glover TW, Smith DI, McKeithan TW: Replication of a common fragile site, FRA3B, occurs late in $S$ phase and is delayed further upon induction: implications for the mechanism of fragile site induction. Hum Mol Genet 1998, 7(4):755-761.

22. Handt O, Baker E, Dayan S, Gartler SM, Woollatt E, Richards RI, Hansen RS: Analysis of replication timing at the FRAIOB and FRA I 6B fragile site loci. Chromosome Res 2000, 8(8):677-688.

23. Freudenreich $\mathrm{CH}$ : Molecular mechanisms of chromosome fragility. Chemtracts - Biochemistry and Molecular Biology 2005, |8: $14 \mid-152$ 
24. Zhang $\mathrm{H}$, Freudenreich $\mathrm{CH}$ : An AT-rich sequence in human common fragile site FRAI6D causes fork stalling and chromosome breakage in S. cerevisiae. Molecular Cell 2007, 27:367-379.

25. Casper AM, Nghiem P, Arlt MF, Glover TW: ATR regulates fragile site stability. Cell 2002, I I I:779-789.

26. Novo FJ, de Mendibil IO, Vizmanos JL: TICdb: a collection of gene-mapped translocation breakpoints in cancer. $B M C$ Genomics 2007, 8:33.

27. Mitelman F, Johansson B, Mertens F: Mitelman Database of Chromosome Aberrations in Cancer. 2008 [http://cgap.nci.nih.gov/ Chromosomes/Mitelman]

28. Smith DI, McAvoy S, Zhu Y, Perez DS: Large common fragile site genes and cancer. Semin Cancer Biol 2007, I 7(I):3I-4I.

29. Arlt MF, Durkin SG, Ragland RL, Glover TW: Common fragile sites as targets for chromosome rearrangements. DNA Repair 2006, 5: II26-II35.

30. Fechter A, Buettel I, Kuehnel E, Schwab M, Savelyeva L: Cloning of genetically tagged chromosome break sequences reveals new fragile sites at 6p2I and |3q22. Int J Cancer 2007, I 20( I I):2359-2367.

31. Arlt MF, Xu B, Durkin SG, Casper AM, Kastan MB, Glover TW: BRCAI is required for common-fragile-site stability via its $G$ 2/M checkpoint function. Mol Cell Biol 2004, 24(I5):670I-6709.

32. Howlett NG, Taniguchi T, Durkin SG, D'Andrea AD, Glover TW: The Fanconi anemia pathway is required for the DNA replication stress response and for the regulation of common fragile site stability. Hum Mol Genet 2005, I 4:693-70I.

33. Durkin SG, Arlt MF, Howlett NG, Glover TW: Depletion of CHK I, but not CHK2, induces chromosomal instability and breaks at common fragile sites. Oncogene 2006, 25(32):438|-4388.

34. Lopes M, Cotta-Ramusino C, Pellicioli A, Liberi G, Plevani P, Muzi-Falconi $M$, Newlon CS, Foiani M: The DNA replication checkpoint response stabilizes stalled replication forks. Nature 200I, 4I 2(6846):557-56I.

35. Tercero JA, Diffley JF: Regulation of DNA replication fork progression through damaged DNA by the Mecl/Rad53 checkpoint. Nature 200I, 4 I 2(6846):553-557.

36. Ozeri-Galai E, Schwartz M, Rahat A, Kerem B: Interplay between ATM and ATR in the regulation of common fragile site stability. Oncogene 2008, 27:2109-2117.

37. Kanaar R, Hoeijmakers JH, van Gent DC: Molecular mechanisms of DNA double strand break repair. Trends Cell Biol 1998, 8( ( 2):483-489.

38. Pfeiffer P, Goedecke W, Obe G: Mechanisms of DNA doublestrand break repair and their potential to induce chromosomal aberrations. Mutagenesis 2000, I5(4):289-302.

39. Gottlich B, Reichenberger S, Feldmann E, Pfeiffer P: Rejoining of DNA double-strand breaks in vitro by single-strand annealing. Eur J Biochem 1998, 258(2):387-395.

40. Lieber MR, Raghavan SC, Yu K: Mechanistic aspects of lymphoid chromosomal translocations. I Natl Cancer Inst Monogr 2008:8-II.

41. Schwartz M, Zlotorynski E, Goldberg M, Ozeri E, Rahat A, le Sage C, Chen BP, Chen DJ, Agami R, Kerem B: Homologous recombination and nonhomologous end-joining repair pathways regulate fragile site stability. Genes Dev 2005, 19(22):27I5-2726.

42. Klugbauer S, Pfeiffer P, Gassenhuber H, Beimfohr C, Rabes HM: RET rearrangements in radiation-induced papillary thyroid carcinomas: high prevalence of topoisomerase I sites at breakpoints and microhomology-mediated end joining in ELEI and RET chimeric genes. Genomics 200I, 73(2): I 49-160.

43. Sutherland GRBE, Richards RI: Fragile Sites. Encyclopedia of Molecular Biology and Molecular Medicine 1996, 2:313-318.

44. Rozier L, El-Achkar E, Apiou F, Debatisse M: Characterization of a conserved aphidicolin-sensitive common fragile site at human 4q22 and mouse 6Cl: possible association with an inherited disease and cancer. Oncogene 2004, 23(4I):6872-6880.

45. Karadeniz NN, Tunca $Y$, Imirzalioglu N: New heritable fragile site at $15 \mathrm{ql} 3$ in both members of a nonconsanguineous couple. Am J Med Genet A 2003, I I 8A(3):290-292.

46. Zuker M: Mfold web server for nucleic acid folding and hybridization prediction. Nucleic Acids Res 2003, 3 I (I3):3406-34I5.

47. Anderson S, DePamphilis ML: Metabolism of Okazaki fragments during simian virus 40 DNA replication. The Journal of biological chemistry 1979, 254(22): I |495- I I504.
48. Hay RT, DePamphilis ML: Initiation of SV40 DNA replication in vivo: location and structure of 5 ' ends of DNA synthesized in the ori region. Cell 1982, 28(4):767-779.
Publish with Bio Med Central and every scientist can read your work free of charge

"BioMed Central will be the most significant development for disseminating the results of biomedical research in our lifetime. "

Sir Paul Nurse, Cancer Research UK

Your research papers will be:

- available free of charge to the entire biomedical community

- peer reviewed and published immediately upon acceptance

- cited in PubMed and archived on PubMed Central

- yours - you keep the copyright
BioMedcentral 